\title{
GEOPIVO: modelo para simulação do desempenho de sistemas de irrigação tipo pivô central
}

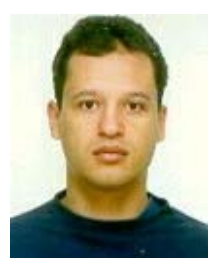

Lineu N. Rodrigues ${ }^{1}$, Fernando F. Pruski ${ }^{2}$, Demetrius D. da Silva ${ }^{3}$ \& Mauro A. Martinez ${ }^{4}$

\author{
${ }^{1}$ Postdoctoral Research Engineer, DS, Department of Biological Systems Engineering, University of Nebraska, Lincoln, NE, \\ USA - 68503. E-mail: lineun@unlserve.unl.edu (Foto) \\ 2 DEA/UFV, CEP 36570-000 Viçosa, MG. Fone: (31) 3899-1912. E-mail: ffpruski@ufv.br \\ ${ }^{3}$ DEA/UFV, CEP 36570-000 Viçosa, MG. Fone: (31) 3899-1904. E-mail: david@ufv.br \\ 4 DEA/UFV, CEP 36570-000 Viçosa, MG. Fone: (31) 3899-1912. E-mail: mmauro@ufv.br
}

Protocolo $082-11 / 7 / 2000$

\begin{abstract}
Resumo: No processo de tomada de decisão dentro da agricultura de precisão, os mapas temáticos desempenham papel de fundamental importância. Especificamente para a irrigação de precisão, que está apenas começando a ser explorada a identificação de áreas com e sem risco de ocorrência de escoamento superficial e de como as gotas produzidas pelos aspersores se distribuem serão de fundamental importância no momento de se decidir como variar a taxa de aplicação dentro da área irrigada. Neste trabalho desenvolveu-se um modelo computacional, baseado no conceito de sistemas de informações geográficas, para confecção daqueles mapas e para auxiliar na tomada de decisão de como variar a taxa de aplicação de água ao longo da área irrigada. Os resultados obtidos mostraram que o modelo pode ser utilizado para representar a variabilidade espacial e temporal da pressão de operação, do diâmetro médio das gotas e das áreas com e sem risco de escoamento superficial, para adequar as condições de operação de pivôs centrais e, também, para prever a ocorrência ou não de escoamento superficial devido a uma alteração no equipamento ou devido a uma mudança no sistema de manejo.
\end{abstract}

Palavras-chave: agricultura de precisão, escoamento superficial, irrigação

\section{GEOPIVO: Simulation model for evaluating center pivot irrigation system performance}

\begin{abstract}
In precision agriculture thematic maps play an important role in the decision making process. When deciding how to vary the application rate inside the irrigated area, especially under precision irrigation, the identification of both areas with and without risk of runoff and the sprinkler droplet size distribution are of great importance. In this research, a computer model was developed based on the geographic information system concept. It can be used to make maps and to assist the user in varying the application rate inside the irrigated area. The results showed that the computer model can be used to represent the spatial and temporal variability of sprinkler pressure, the sprinkler droplet size, and the areas with and without risk of runoff, and also to help the user to redesign and to foresee runoff due to a change in the pivot or in the system management.
\end{abstract}

Key words: precision agriculture, runoff, irrigation

\section{INTRODUÇÃO}

Da área total irrigada no país, em 39,2\% são utilizados sistemas de irrigação por aspersão (Christofidis, 1997). Entre esses, o pivô central tem-se destacado. Embora tenha sido patenteado no estado de Nebraska, EUA, no início dos anos 50, a sua fabricação no Brasil teve início apenas no final da década de 70. Trabalhando-se com os dados apresentados por Christofidis (1997) conclui-se que no Brasil a área irrigada por pivô central representa, atualmente, mais da metade da área total irrigada por aspersão.

A aplicação de modelos computacionais ao dimensionamento e manejo de sistemas de irrigação por aspersão do tipo pivô central constitui-se em uma valiosa ferramenta, a qual permite ao projetista visualizar o resultado advindo, por exemplo, de uma troca de aspersores, antes da sua implantação no campo. Esses modelos têm contribuído para melhorar a eficiência dos sistemas de irrigação.

A utilização dos sistemas de posicionamento global (GPS) e de informação geográfica (SIG) no setor agrícola tem possibilitado aplicar diferentes estratégias de manejo dentro da mesma área cultivada. Com o surgimento dessa nova forma de otimização da produção agrícola, chamada agricultura de precisão, antigos conceitos estão sendo modificados e outros incorporados ao processo e, com isto, a visão de como abordar e manejar o sistema agrícola tem-se modificado. 
Dentro deste contexto, a aplicação de água a uma taxa variada (irrigação de precisão) está apenas começando a ser explorada. Sistemas de irrigação auto propelidos, como pivô central e "linear move", são particularmente adequados para a condição de irrigação de precisão devido, principalmente, aos seus atuais níveis de automação e grande área irrigada com uma única lateral. Utilizando-se controles, sensores e ferramentas de tomada de decisão apropriados, esses sistemas de irrigação podem ser manejados de forma a aplicar, dentro da área irrigada, os diferentes requerimentos por água e fertilizantes (Evans, 1997).

Apesar da alta uniformidade de aplicação de água, típica dos pivôs centrais, é comum obter-se considerável variação na produção dentro da mesma área cultivada. Tal variação é, freqüentemente, atribuída à variabilidade espacial na capacidade do solo em reter água e nutrientes; entretanto, outro fator que deve ser considerado dentro desse contexto e a ocorrência do escoamento superficial em algumas regiões dentro da área cultivada.

Para os agricultores que estão adotando essa nova técnica os mapas temáticos, especialmente os mapas de rendimento das culturas, são de grande valia no processo de tomada de decisão. Todavia, no momento de decidir como variar a taxa de aplicação ao longo da área irrigada, mapas indicativos da variação de pressão de operação dos aspersores, do diâmetro de gota e de áreas com ou sem risco de escoamento superficial são de mais utilidade que os mapas de rendimento. Tais mapas podem, ainda, ser utilizados para avaliar a variação temporal na pressão de operação dos aspersores e no diâmetro de gotas devida ao envelhecimento do sistema e o impacto no escoamento superficial devido a troca de aspersores de alta pressão por difusores e/ou mudança nas práticas de preparo do solo.

Tendo em vista os fatores abordados anteriormente, desenvolveu-se o presente trabalho cujos objetivos foram: a) desenvolver um modelo computacional, baseado no conceito de sistemas de informações geográficas, de fácil utilização e baixo custo para auxiliar na tomada de decisão de como variar a taxa de aplicação de água ao longo da área irrigada; b) utilizar o modelo desenvolvido para simular o desempenho de sistemas de irrigação tipo pivô central operando em terrenos com topografia irregular.

\section{MATERIAL E MÉTODOS}

\section{Programa computacional}

Um programa computacional, denominado GEOPIVO, foi desenvolvido em linguagem Object Pascal, com o compilador Delphi 3.0; trata-se de um programa interativo que permite ao usuário escolher diversas opções de configuração do sistema.

Antes de executar o programa, o usuário necessita criar um arquivo tipo texto com as seguintes informações: linha 1 - posição dos aspersores ao longo da lateral do pivô; linha 4 - vazão de cada aspersor ao longo da lateral do pivô; linha 9 - diâmetro de cada trecho entre dois aspersores e linha 11 - diâmetro do bocal dos aspersores ao longo da lateral do pivô.

\section{Cálculo da pressão de operação dos aspersores}

A combinação de pressão e diâmetro do bocal determinam o diâmetro das gotas, sua distribuição na área molhada e o diâmetro de alcance do jato de água emitido pelo aspersor. Uma vez que o diâmetro do bocal é invariável (ao longo da circunferência percorrida por um determinado aspersor), a variação da pressão de operação é a única causa da variação daquelas variáveis.

Para calcular a pressão em cada aspersor ao longo da lateral do pivô relativa a uma determinada posição da lateral dentro da área irrigada, levando-se em consideração as mudanças na topografia do terreno, utilizou-se a equação

$$
\mathrm{P}_{\mathrm{i}, \mathrm{j}+1}=\mathrm{P}_{\mathrm{i}, \mathrm{j}}-\Delta \mathrm{H}_{\mathrm{i}, \mathrm{j}} \pm \mathrm{Z}_{\mathrm{i}, \mathrm{j}}
$$

em que:

$P_{i, j+1}$ - pressão no aspersor de ordem $i, j+1$, m.c.a

$\mathrm{P}_{\mathrm{i}, \mathrm{j}}$ - pressão no aspersor de ordem i,j, m.c.a

$\Delta \mathrm{H}_{\mathrm{i}, \mathrm{j}}$ - perda de carga no trecho entre os aspersores $\mathrm{i}, \mathrm{j}$ e $\mathrm{i}, \mathrm{j}+1$, m.c.a

$Z_{i, j} \quad$ - desnível do trecho entre os asperores i,j e i,j+1, m

i - posição da lateral do pivô central dentro da área irrigada

j - posição do aspersor ao longo da lateral do pivô central

Para calcular a perda de carga no trecho entre os aspersores i,j e i,j+1, utilizou-se a equação de Darcy-Weisbach, a qual pode ser representada, de forma generalizada para qualquer trecho de tubulação, pela seguinte equação:

$$
\Delta H_{j}=\frac{8}{g \pi^{2}} f_{j} \frac{Q_{j}^{2}}{D_{j}^{5}} L_{j}
$$

em que:

g - aceleração devido à gravidade, $\mathrm{m} \mathrm{s}^{-2}$

$\mathrm{f}_{\mathrm{j}} \quad$ - fator de atrito da fórmula de Darcy-Weisbach para o trecho de ordem $\mathrm{j}$, adimensional

$Q_{j} \quad$ - vazão do trecho de ordem $j, m^{3} s^{-1}$

$D_{j} \quad$ - diâmetro interno do segmento de tubulação de ordem j, $m$

$\mathrm{L}_{\mathrm{j}} \quad$ - comprimento do trecho de ordem $\mathrm{j}, \mathrm{m}$

Segundo Churchill, citado por Allen (1996), o fator de atrito da equação de Darcy-Weisbach pode ser calculado pela equação

$$
\mathrm{f}_{\mathrm{j}}=8\left\{\left(\frac{8}{\mathrm{NR}_{\mathrm{ej}}}\right)^{12}+\left[\frac{1}{(\mathrm{~A}+\mathrm{B})^{1,5}}\right]\right\}^{1 / 12}
$$

sendo

$$
\begin{gathered}
\mathrm{NR}_{\mathrm{ej}}=\frac{4 \mathrm{Q}_{\mathrm{j}}}{\pi \mathrm{D}_{\mathrm{j}}} \frac{1}{v} \\
\mathrm{~A}=\left\{2,457 \ln \left[\left(\left(\frac{7}{\mathrm{NR}_{\mathrm{ej}}}\right)^{-0,9}+0,27\left(\frac{\varepsilon}{\mathrm{D}_{\mathrm{j}}}\right)\right)^{-1}\right]\right\}^{16}
\end{gathered}
$$




$$
\mathrm{B}=\left(\frac{37.530}{\mathrm{NR}_{\mathrm{ej}}}\right)^{16}
$$

em que:

$\mathrm{NR}_{\mathrm{ej}}$ - número de Reynolds, adimensional

$v \quad$ - coeficiente de viscosidade cinemática da água, $\mathrm{m}^{2} \mathrm{~s}^{-1}$

$\varepsilon \quad$ - rugosidade equivalente, $\mathrm{m}$

Segundo Neves (1989), desprezando-se a variação da densidade da água com a temperatura, o coeficiente de viscosidade cinemática da água pode ser calculado pela equação

$$
v=\frac{0,00000178}{\left(1+0,0337 \mathrm{t}_{\mathrm{a}}+0,000221 \mathrm{t}_{\mathrm{a}}{ }^{2}\right)}
$$

em que $\mathrm{t}_{\mathrm{a}}$ é a temperatura média da água, ${ }^{\circ} \mathrm{C}$.

Para calcular o desnível do trecho entre dois aspersores i,j e i,j+1, utilizou-se a equação

$$
Z_{i, j}=S_{j}\left(\frac{T_{i, j}-T_{i, j+1}}{L v}\right)
$$

em que:

$\mathrm{S}_{\mathrm{j}} \quad$ - distância do aspersor de ordem $\mathrm{j}$ à torre de ordem $\mathrm{j}, \mathrm{m}$

$\mathrm{T}_{\mathrm{i}, \mathrm{j}} \quad$ - cota da torre de ordem $\mathrm{i}, \mathrm{j}, \mathrm{m}$

$\mathrm{T}_{\mathrm{i}, \mathrm{j}+1}$ - cota da torre de ordem $\mathrm{i}, \mathrm{j}+1, \mathrm{~m}$

$\mathrm{Lv}$ - comprimento do vão entre torres, $m$

\section{Cálculo do diâmetro médio das gotas}

$\mathrm{O}$ diâmetro das gotas produzidas pelos aspersores exerce grande influência na eficiência dos sistemas de irrigação do tipo pivô central. Gotas menores estão associadas a maiores perdas por deriva, e gotas maiores à maior probabilidade de ocorrência de escoamento superficial.

Uma vez que os catálogos apresentados pelos fabricantes normalmente não informam a respeito desse parâmetro, o programa disponibiliza duas alternativas para sua estimativa, em que a primeira, descrita por Rodrigues (1999), utiliza a função de densidade de probabilidade log-normal a três parâmetros, sendo os parâmetros da distribuição calculados pelas equações propostas por von Bernuth (1985) e a segunda utiliza a equação proposta por Kincaid (1996). Este autor utilizou instrumento a laser para analisar a distribuição do diâmetro de gotas de aspersores utilizados na irrigação e sugere utilizar a Eq. 9 para descrever a distribuição de gotas dos principais aspersores utilizados na irrigação.

$$
D_{g 50}=a_{d}+b_{d}\left(\frac{D_{b i}}{P_{i}}\right)
$$

em que:

$\mathrm{D}_{\mathrm{g} 50}$ - diâmetro médio das gotas, $\mathrm{mm}$

$a_{d}, b_{d}$ - coeficientes de ajuste da equação do diâmetro médio das gotas
$\mathrm{D}_{\mathrm{bi}}$ - diâmetro do bocal do aspersor de ordem i, mm

$\mathrm{P}_{\mathrm{i}} \quad$ - pressão no aspersor de ordem i, mca

Na Tabela 1 apresentam-se os valores, em função do tipo do aspersor utilizado, dos coeficientes $a_{d} e b_{d}$.

Tabela 1. Valores dos coeficientes da equação proposta por Kincaid (1996) para o cálculo do diâmetro médio das gotas

\begin{tabular}{lrr}
\hline \multicolumn{1}{c}{ Modelo do Aspersor } & $\mathrm{a}_{\mathrm{d}}$ & \multicolumn{1}{c}{$\mathrm{b}_{\mathrm{d}}$} \\
\hline Impacto, com diâmetro de bocal variando de 3 a 6 mm & 0,31 & 11.900 \\
Impacto, com diâmetro de bocal variando de 9 a $15 \mathrm{~mm}$ & 1,30 & 2.400 \\
Difusor & 0,82 & 620 \\
\hline
\end{tabular}

Para confeccionar o mapa de variação de diâmetro médio das gotas, a posição crítica do pivô dentro da área a ser irrigada é tomada como referência, ou seja, aquela posição utilizada no dimensionamento do equipamento (ponto mais elevado em relação à última torre). O diâmetro médio das gotas, utilizado como referência, é então calculado em função da metodologia escolhida pelo usuário, sendo utilizados o diâmetro médio dos bocais e a pressão média de operação.

\section{Intensidade de precipitação máxima admissível}

Denomina-se intensidade de precipitação máxima admissível o maior valor de precipitação que se pode aplicar em uma área sem provocar escoamento superficial.

A estimativa desse parâmetro é feita com base na metodologia desenvolvida por Rodrigues et al. (1999). De acordo com esses autores a intensidade de precipitação máxima admissível pode ser estimada utilizando-se as Eqs. 10, 11 e 12.

$$
\begin{gathered}
\mathrm{i}_{\text {pma }}=\frac{4,47 \mathrm{~K}_{\mathrm{h}}\left(\mathrm{A}_{\mathrm{s}}-\mathrm{L}(\mathrm{t})-\mathrm{S}_{\mathrm{w}} \theta_{\mathrm{d}}\right) \mathrm{L}_{\mathrm{p}}}{\left[\mathrm{A}_{\mathrm{s}}-\mathrm{L}(\mathrm{t})\right]\left[\mathrm{L}_{\mathrm{p}}(\xi)-78,96 \mathrm{~L}^{2}(\mathrm{t})\right]^{0,5}} \\
\Omega=\frac{\left.44,13 \mathrm{i}_{\text {pma }} \mid \mathrm{L}_{\mathrm{p}}-2 \mathrm{~L}(\mathrm{t})\right]}{5\left[\mathrm{~L}_{\mathrm{p}} \xi-78,96 \mathrm{~L}^{2}(\mathrm{t})\right]^{0,5} \mathrm{~L}_{\mathrm{p}}}+\frac{\mathrm{K}_{\mathrm{h}} \mathrm{S}_{\mathrm{w}} \theta_{\mathrm{d}}}{\left[\mathrm{A}_{\mathrm{s}}-\mathrm{L}(\mathrm{t})\right]^{2}} \\
\frac{\mathrm{d}(\Omega)}{\mathrm{d}(\mathrm{L}(\mathrm{t}))}=\frac{2 \mathrm{~K}_{\mathrm{h}} \mathrm{S}_{\mathrm{w}} \theta_{\mathrm{d}}}{\left[\mathrm{A}_{\mathrm{s}}-\mathrm{L}(\mathrm{t})\right]^{3}}-\frac{1853,80 \mathrm{i}_{\mathrm{pma}} \mathrm{L}_{\mathrm{p}}}{5\left\{\mathrm{~L}_{\mathrm{p}}\left[\xi-78,96 \mathrm{~L}^{2}(\mathrm{t})\right]^{1,5}\right\}}
\end{gathered}
$$

sendo:

$$
\xi=78,96 \mathrm{~L}(\mathrm{t})+1,26 \mathrm{~L}_{\mathrm{p}}
$$

em que:

$\mathrm{i}_{\mathrm{pma}} \quad$ - intensidade de precipitação máxima admissível, $\mathrm{mm} \mathrm{h}^{-1}$

$\mathrm{K}_{\mathrm{h}}$ - condutividade hidráulica do solo saturado, $\mathrm{mm} \mathrm{h}^{-1}$

$\mathrm{A}_{\mathrm{s}} \quad$ - armazenamento superficial, $\mathrm{m}$

$\mathrm{L}(\mathrm{t})$ - lâmina aplicada ao solo em função do tempo, mm

$\mathrm{S}_{\mathrm{w}} \quad$ - potencial matricial médio na frente de umedecimento, $\mathrm{mm}$

$\theta_{\mathrm{d}} \quad$ - déficit de umidade no solo na saturação, $\mathrm{cm}^{3} \mathrm{~cm}^{-3}$

$\mathrm{L}_{\mathrm{p}} \quad$ - lâmina total a ser aplicada, $\mathrm{mm}$ 
Estas equações devem ser resolvidas pela técnica numérica de Newton-Raphson, cujo procedimento consiste em se atribuir um valor inicial para $\mathrm{L}(\mathrm{t})$ na Eq. 10 e calcular o valor da intensidade de precipitação máxima admissível. Os valores de $\mathrm{L}(\mathrm{t})$ e de $\mathrm{i}_{\text {pma }}$ são, então, substituídos nas Eqs. 11 e 12, sendo o erro calculado pela Eq. 14 . O procedimento se encerrará quando o módulo do erro for inferior a 0,001 . Recomenda-se, com o intuito de otimizar o tempo computacional, iniciar o procedimento com um valor de $\mathrm{L}(\mathrm{t}) \geq \mathrm{L}_{\mathrm{p}} / 2$.

$$
\text { Erro }=\frac{\Omega}{\mathrm{d}(\Omega) / \mathrm{d}(\mathrm{L}(\mathrm{t}))}
$$

\section{Simulação do desempenho de sistemas de irrigação por aspersão tipo pivô central}

Na Figura 1 tem-se a imagem de elevação digital do terreno para a área estudada, com a identificação do local onde o pivô central foi instalado.

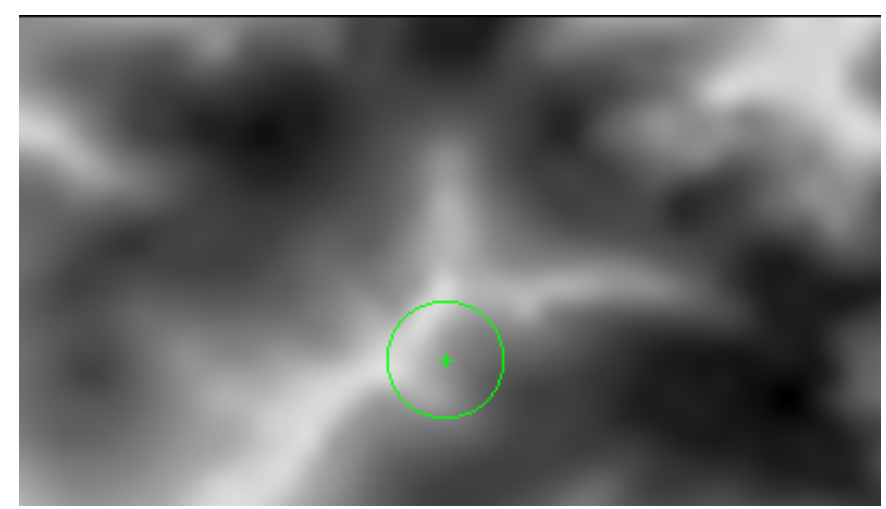

Figura 1. Imagem com o mapa de elevação digital do terreno para a área estudada, destacando-se o local onde o pivô central foi instalado

Para simular o desempenho do programa computacional as seguintes condições foram testadas: dois modelos de aspersores (impacto de alta pressão e difusor), pressão de operação aplicada no meio e no final da lateral, com e sem o uso de válvulas reguladoras de pressão. A função de densidade de probabilidade log-normal a três parâmetros (ULLN) foi utilizada para estimar o diâmetro médio das gotas. As variáveis de entrada relacionadas ao pivô foram: raio $=250 \mathrm{~m} ; \mathrm{L}_{\mathrm{p}}=10 \mathrm{~mm}$; coeficiente de descarga do bocal do aspersor $=0,9$; altura do aspersor em relação ao solo $=3,5 \mathrm{~m}$; ângulo de inclinação do bocal $=6$ graus; temperatura da água $=20^{\circ} \mathrm{C}$. As variáveis de entrada relacionadas ao solo utilizadas foram: As $=0 \mathrm{~mm}$; $\mathrm{K}_{\mathrm{h}}=27 \mathrm{~mm} \mathrm{~h}^{-1} ; \theta_{\mathrm{d}}=0,17 ; \mathrm{S}_{\mathrm{w}}=180 \mathrm{~mm}$.

\section{RESULTADOS E DISCUSSÃO}

Nas Figuras 2 e 3 encontram-se os mapas de variação da pressão de operação dos aspersores dentro da área irrigada.

A variação da topografia do terreno provoca variação da pressão de operação dos aspersores. A visualização de como a pressão varia dentro da área irrigada é de fundamental importância na avaliação do desempenho do equipamento, uma vez que a pressão influencia diretamente o diâmetro médio da gota $\mathrm{e}$

este, por sua vez, está relacionado com as perdas por deriva (evaporação e arrastamento pelo vento) e com o selamento superficial. Ressalta-se, também, a influência da pressão no diâmetro de alcance do jato de água, o qual está relacionado com a maior ou menor intensidade de precipitação, e, em conseqüência, com a maior ou menor probabilidade de ocorrência do escoamento superficial.

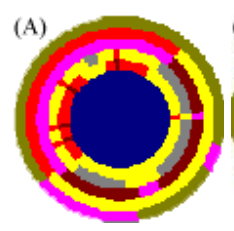

$\mathrm{PO} \leq 0,80 \mathrm{PS}$

$0,90 \mathrm{PS}<\mathrm{PO} \leq 0,95 \mathrm{PS}$

$1,05 \mathrm{PS}<\mathrm{PO} \leq 1,10 \mathrm{PS}$

$1.20 \mathrm{PS}<\mathrm{PO}$

Figura 2. Variação espacial da pressão de operação (PO) dos aspersores de um pivô central em relação a pressão de serviço (PS) para as seguintes configurações de pivôs: aspersores de impacto de alta pressão com pressão de serviço aplicada no meio (A e B) e no final (C e D) da lateral sem (A e C) e com (B e D) válvulas reguladoras de pressão
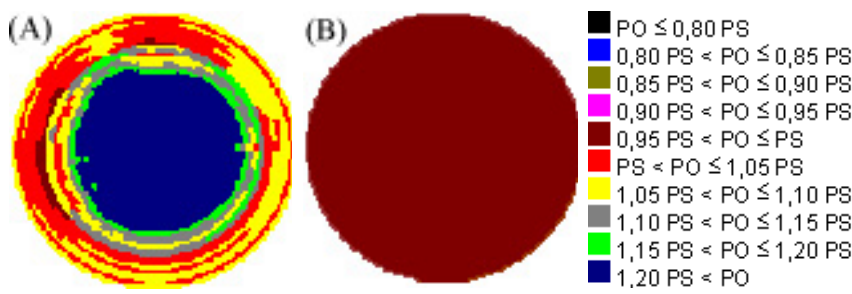

Figura 3. Variação da pressão de operação (PO) dos aspersores de um pivô central em relação a pressão de serviço (PS) para as seguintes configurações de pivôs: aspersores tipo difusor com pressão de serviço aplicada no final da lateral sem (A) e com (B) válvulas reguladoras de pressão

Os mapas de variação de pressão podem ser utilizados para avaliar as conseqüências advindas da redução da pressão, com o intuito de reduzir os gastos com energia. Por fim, eles podem ser utilizados para verificar a necessidade ou não de utilizar válvulas reguladoras de pressão (VRP). Segundo o critério atualmente adotado, a utilização desses dispositivos faz-se necessária sempre que houver uma variação da pressão maior que $20 \%$ da pressão de serviço.

Nas Figuras 2A, 2B e 2C observa-se a influência da topografia do terreno na pressão de operação dos aspersores. Como era de se esperar, os equipamentos dotados de válvula reguladora de pressão apresentaram menor variação da pressão de operação (Figuras 2B e 2D). Para um pivô sem VRP (Figura 2A), houve aspersores trabalhando tanto com pressão de operação inferior a $10 \%$ da pressão de serviço (aspersor localizado na extremidade final do pivô) como com pressão superior a $20 \%$ da pressão de serviço (aspersores próximos do centro do pivô).

Os pivôs dotados de VRP com PS aplicada no final da lateral apresentam todos os aspersores trabalhando à pressão de serviço de projeto (Figura 2D); já aqueles com PS sendo aplicada no meio da lateral apresentam alguns aspersores localizados 
na extremidade final do pivô trabalhando com pressão de operação inferior à pressão de projeto (Figura 2B).

Pode-se verificar, também, nas Figuras $2 \mathrm{~A}$ e $2 \mathrm{C}$ que a variação na pressão de operação dos aspersores, tanto na trajetória circunferencial como ao longo da lateral do pivô, é menor quando a PS é aplicada no final da lateral, permitindo concluir-se que, se for adotado como critério de tomada de decisão a uniformidade da pressão de operação, a melhor estratégia de dimensionamento é aplicar a PS no final da lateral, embora o gasto com energia seja maior nestes equipamentos. Tal constatação é válida tanto para pivôs com VRP quanto para pivôs sem VRP.

Os pivôs dotados de difusores são mais sensíveis às variações no terreno (Figura 3A). Embora não seja ilustrado neste trabalho, constatou-se que, quando se utilizam difusores e se aplica a PS no meio da lateral, a influência da topografia na pressão de operação torna-se ainda mais acentuada.

Nas Figuras 4 e 5 apresentam-se os mapas de variação do diâmetro médio da gota.

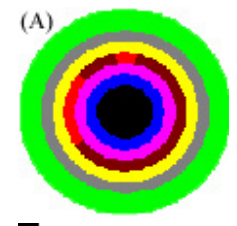

$\mathrm{Dm} \leq 0,80 \mathrm{D}_{3}$

$0,90 \mathrm{D}_{20}<\mathrm{Dm} \leq 0,95 \mathrm{D}_{30}$

$1,05 D_{3,0}<D m \leq 1,10 D_{3}$

$1.20 \mathrm{D}_{\mathbf{v}}<\mathrm{Dm}$

Figura 4. Variação do diâmetro médio das gotas $\left(\mathrm{D}_{\mathrm{g} 50}\right)$ para as seguintes configurações de pivôs: aspersores de impacto de alta pressão com pressão de serviço aplicada no meio (A e B) e no final (C e D) da lateral sem (A e C) e com (B e D) válvulas reguladoras de pressão
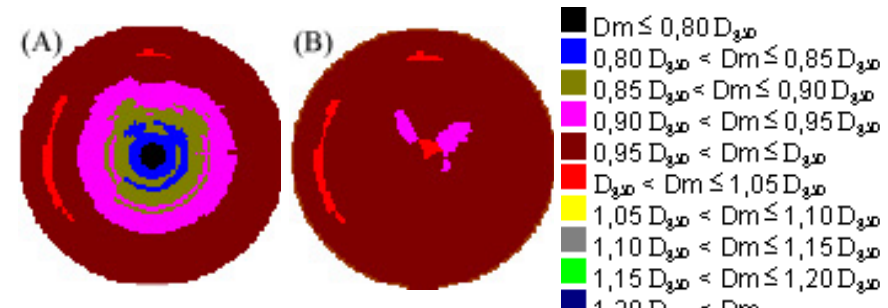

Figura 5. Variação do diâmetro médio das gotas $\left(\mathrm{D}_{\mathrm{g} 50}\right)$ para as seguintes configurações de pivôs: aspersores tipo difusor com pressão de serviço aplicada no final da lateral sem (A) e com (B) válvulas reguladoras de pressão

A visualização dos mapas de variação do diâmetro das gotas permite se fazer diversas análises como, por exemplo, verificar as regiões mais propensas à ocorrência do ES e à perda por deriva. A partir dessa análise, o projetista pode tomar medidas corretivas, como a adequação das condições de funcionamento do pivô central ou, ate mesmo, a construção de bacias de armazenamento nas áreas mais sujeitas à ocorrência de ES.

A diferença básica entre as Figuras 4A e 4B é que a primeira é influenciada diretamente pela variação no diâmetro do bocal dos aspersores e indiretamente pela variação da topografia; já a segunda é influenciada apenas pela variação no diâmetro do bocal dos aspersores.
Observa-se, nas Figuras 4A e 4B, que a variação da topografia do terreno teve pouca influência no diâmetro médio das gotas. Nota-se que o diâmetro médio das gotas foi menor que o $\mathrm{D}_{\mathrm{g} 50}$ tomado como referência em posições próximas ao centro do pivô e superior a este em posições mais afastadas do centro do pivô, tanto para pivôs com VRP como para pivôs sem VRP. Este resultado também era esperado, uma vez que o $D_{g 50}$ tomado como referência foi calculado utilizando-se o diâmetro médio dos bocais dos aspersores. Como em pontos próximos ao centro do pivô os diâmetros dos bocais dos aspersores são menores que o diâmetro médio do bocal, é natural que haja menores diâmetros de gotas nessas posições. $\mathrm{Na}$ extremidade oposta ao centro do pivô observa-se o contrário, isto é, maiores diâmetros de bocais com maiores diâmetros de gota.

Na Figura 4C observa-se na extremidade do pivô a influência da topografia sobre o diâmetro médio das gotas. Nota-se que, em quase toda a circunferência percorrida pelo pivô, as gotas produzidas pelos aspersores apresentaram diâmetro da gota médio maior que o diâmetro médio tomado como referência (cor azul-escuro); entretanto, em uma pequena faixa (cor verde) houve redução no $\mathrm{D}_{\mathrm{g} 50}$. Esta redução no valor do diâmetro médio se deve a um aumento da pressão de operação, provocado por uma depressão no terreno.

Pivôs com pressão de serviço aplicada no final da lateral apresentaram maior variação de diâmetro médio de gota sendo, portanto, mais influenciados pela topografia do terreno (Figura 4C). Nesses equipamentos, a utilização de VRP contribuiu de forma mais efetiva para uniformizar o $\mathrm{D}_{\mathrm{g} 50}$ produzido pelos aspersores reduzindo, assim, a influência da topografia.

Observa-se que pivôs equipados com difusores produzem $\mathrm{D}_{\mathrm{g} 50}$ mais uniformes, isto é, são menos influenciados pela variação da topografia (Figura 5A). Na Figura 5B observa-se a influência indireta da topografia e da variação do diâmetro do bocal no $\mathrm{D}_{\mathrm{g} 50}$, mesmo em equipamentos dotados de VRP.

Nas Figuras 6 e 7 apresentam-se os mapas de risco de escoamento superficial. Fazendo-se a análise pelo critério de
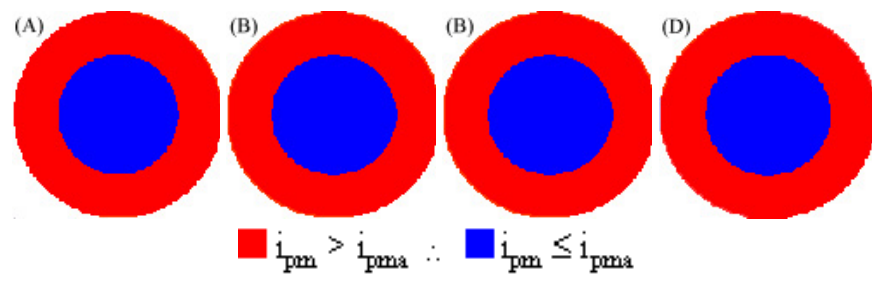

Figura 6. Áreas com e sem risco de ocorrência de escoamento superficial (ES) para a seguinte configuração de pivô: aspersores de impacto de alta pressão com pressão de serviço aplicada no meio (A e B) e no final (C e D) da lateral sem (A e C) e com (B e D) válvulas reguladoras de pressão

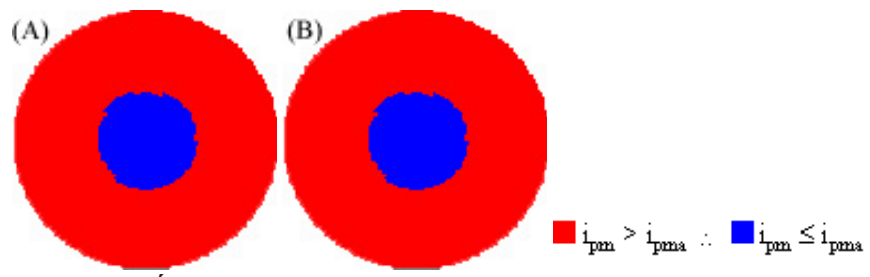

Figura 7. Áreas com e sem risco de ocorrência de escoamento superficial (ES) para a seguinte configuração do pivô: aspersores tipo difusor com pressão de serviço aplicada no final da lateral sem (A) e com (B) válvulas reguladoras de pressão 
risco de ocorrência de escoamento superficial, pode-se constatar que não houve diferença expressiva quando a pressão de serviço foi aplicada no meio ou no final da lateral (Figuras 6A e 6C). Isto ocorreu por ter-se considerado, durante as simulações, apenas um tipo de solo e, também, devido a resolução do mapa de elevação digital utilizado $(10 \mathrm{~m})$. Pelo mesmo critério, constatou-se que, também, não houve diferença expressiva entre os pivôs com ou sem válvulas reguladoras de pressão (Figuras 6A e 6B).

Em todos esses casos, mantendo-se as mesmas configurações dos equipamentos, o maior pivô que poderia ser instalado nessa área, sem provocar ES, seria de 142,8 $\mathrm{m}$ de raio. Pivôs equipados com aspersores tipo difusor apresentam maior risco de ocorrência de ES, o que pode ser observado na Figura 7.

Nesses equipamentos, a utilização de VRP contribuiu para aumentar o risco de ocorrência de ES, o que pode ser verificado pela comparação das áreas em azul das Figuras 7A e 7B. Utilizando-se VRP, o maior comprimento permissível é de $77,6 \mathrm{~m}$; já para um pivô sem VRP, este valor passa a ser de 93,3 m. Este resultado se deve à menor pressão de operação dos aspersores próximos ao centro do pivô nos equipamentos com VRP. Havendo menor pressão, eles terão, por conseguinte, maior diâmetro médio das gotas, o que implica em maior selamento superficial e menor valor de intensidade de precipitação máxima admissível. Este fator, aliado à redução do diâmetro de alcance, provocado também pela redução da pressão de operação, conduz ao resultado obtido.

Para pivôs equipados com difusores, os mesmos resultados seriam obtidos se fosse utilizada a equação para cálculo do $\mathrm{D}_{\mathrm{g} 50}$ proposta por Kincaid (1996) em vez da distribuição ULLN; entretanto, para os casos de pivô com aspersores de impacto de alta pressão, os resultados seriam diferentes. Uma vez que o $\mathrm{D}_{\mathrm{g} 50}$ calculado pela equação de Kincaid (1996) é inferior ao $\mathrm{D}_{g 50}$ obtido pela distribuição ULLN com os parâmetros calculados pelas equações propostas por von Bernuth (1985), se aquela equação fosse utilizada ao invés desta, ter-se-ia, neste caso, menor área com risco de ocorrência de ES.

Embora a irrigação de precisão esteja ainda em fase de desenvolvimento, espera-se, em alguns anos, que as indústrias desenvolvam e ponham a nível comercial um pivô capaz de variar a taxa de aplicação de acordo com a sua posição no campo. Neste contexto, o programa poderá ser utilizado como ferramenta para auxiliar na variação da taxa de aplicação de água dentro da área irrigada.

\section{CONCLUSÕES}

Os resultados obtidos permitiram as seguintes conclusões:

1. O modelo pode ser utilizado no estudo da variabilidade espacial e temporal da pressão de operação, do diâmetro médio das gotas e das áreas com e sem risco de escoamento superficial.

2. O programa computacional pode ser utilizado para adequar as condições de operação de pivôs centrais e, até mesmo, identificar áreas onde bacias de armazenamento devem ser construídas.

3. O modelo pode ser utilizado para antever a ocorrência ou não de escoamento superficial devido a uma alteração no equipamento ou devido a uma mudança no sistema de manejo.

4. Pivôs com pressão de serviço aplicada no final da lateral foram mais influenciados pela topografia do terreno.

5. Pelo critério de risco de ocorrência de escoamento superficial, não houve diferenças expressivas entre os pivôs com pressão de serviço aplicada no meio ou no final da lateral nem entre os pivôs com ou sem válvulas reguladoras de pressão.

\section{LITERATURA CITADA}

Allen, R.G. Relating the Hazen-Williams and Darcy-Weisbach friction loss equations for pressurized irrigation. Applied Engineering in Agriculture, St. Joseph, v.12, n.6, p.685-693, 1996.

Christofidis, D. Situação das áreas irrigadas no Brasil. (Versão Preliminar). Brasília, DF: MMA/SRH, 1997. Não paginado. (Programa Nacional de Irrigação e Drenagem).

Evans, R.G. If you build it, will it work? Testing precision centerpivot irrigation. GPS World Magazine, Eugene, p.10-17, 1997.

Kincaid, D.C. Spraydrop kinetic energy from irrigation sprinklers. Transactions of the ASAE, St. Joseph, v.121, n.2, p.152-158, 1996.

Neves, E.T. Curso de hidráulica. 9a . ed. Porto Alegre: Editora Globo, 1989.577p.

Rodrigues, L.N.; Pruski, F.F.; Martinez, M.A.; Silva, D.D. Metodologia para estimativa da intensidade de precipitação máxima admissível em pivô central. Engenharia Agrícola, Jaboticabal, v.19, n.2, p.151-162, 1999.

von Bernuth. A physically based analysis of potential runoff under center pivot irrigation incorporating infiltration reduction. Lincoln: University of Nebraska, 1985. 124 p. PhD Thesis 